\title{
ENCERRAMENTO DO ANO LETIVO
}

Encerrando o ano letivo de 1934, a Faculdade de Direito celebrou, a 14 de Novembro, varias solenidades, entre as quais a inauguração do novo salão "Dr. João Mendes Junior", amplo anfiteatro situado no andar terreo do novo predio ora em construçāo.

A 9 horas, nesse anfitreatro, reuniram-se os professores, alunos e convidados, entre as quais os srs. dr. Marcio Munhoz, secretario da Educaçāo e respondendo, áquela data, pelo expediente da Interventoria, dr. Francisco Machado de Campas, secretario da Viação, dr. Adalberto Bueno Neto, secretario da Agricultura, dr. Christiano Altenfelder Silva, chefe de Policia, representantes de outras altas autoridades estaduais e municipais.

Aberta a sessão, o dr. Waldemar Ferreira, vice-diretor da Faculdade, em exercicio, passou a presidencia ao reitor da Universidade de S. Paulo, dr. Reynaldo Porchat.

Foi então dada a palavra ao professor dr. Theophilo Benedicto de Sousa Carvalho, que pronunciou o seguinte discurso:

\section{Discurso do Prof. Sousa Carvalho}

Senhores,

A nossa lei estatutaria estabelece duas preleçōes, a meu ver sui generis: uma inaugural c outra de encerramento do curso, confiando a primeira ao Mestre mais novo e a segunda ao mais velho.

Essas preleções se extremam no tempo, mas, se aliam e se completam no pensamento.

Bem acertadamente andou essa lei, confiando ao mais moço, ao que se acha mais proximo da mocidade, o encargo de concitar esta ás lutas da inteligencia, a iniciar-se, provocando-lhe o entusiasmo e a excitação da alma tão proprias dos verides anos,

\footnotetext{
"A alma é fogo, que nutrir se deve $E$ que se apaga, se não cresce a flama!
}

(vOLTAiRf) 
e ao mais velho incumbindo de apreciar, apenas, o perfume das flores colbidas durante tão edificante quão meritoria peleja travada neste jardim do Pensamento e da Honestidade Profissional, que é esta nossa querida Faculdade de Direito, já quando os combatentes avançaram mais um ano em direção á minha velhice.

O mais moço já cumpriu o scu dever com o brilho que era de esperar. Agora, me esforçarei por cumprir tambem o meu de velho.

Se Deus me não ajudar de modo a merecer, ao menos, a benevolencia dos que me ouvem, responda pelo castigo sofrido a nossa lei estatutaria que para aqui me mandou.

Não pretendo, na hora presente, relembrar os aspectos das ciencias aqui ministradas e as vantagens do seu estudo. Nem reviver as excelencias da ars boni et oqui; nem que o Direito Constitucional é o compendio dos direitos do cidadão para com os poderes publicos, mostrando como nos regimes liberais a soberania só cabe ao povo e este a exercita manejando a formidavel arma do voto livre e secreto; nem que o Direito Civil é o compendio das faculdades que cabem ao individuo nas relações de ordem meramente privada, constituindo assim, como que, a carta de alforria do cidadão; nem que o Direito Comercial, lei de exceção, é a regra da vida mercantil, e que HEEREN, na sua monumental "Politica e Comercio dos Povos da Antiguidade", referindo-se á unidade da industria moderna, que formou do genero humano como que a maior natio, vê no comercio vastissima serie de operações complicadas uma como gigantesca engrenagem cujas molas se completam e mutuamente se auxiliam: - porque tudo isto já os meus colegas fizeram sentir á mocidade academica pontificando nas suas catedras e o seleto auditorio, que me suporla nesta tribuna, bem o sabe.

Não devo, porém, deixar passar a ultima preleção do curso juridico, sem ilustrar este meu modesto discurso com opontuna advertencia de sabio Mestre, inspirado em Bellime e Thercelin.

"Não demos curso ao celebre QUID HOC AD EDICTUM PRETORIS de Cujacio; derrubemos esta trincheira, com que os praticos de hoje querem manter-se radicados nas fatos e na experiencia. Sem a teoria nada se pode fazer de permanente, porque não é pelas colecões de arestos que a Ciencia ha de prosperar.

Se ao cidadão se pode aconselhar, que obedeça, sem raciocinar, á lei do pais, ao cultor da Ciencia do Direito o raciocinio nunca é dispensavel; para ele a lei não é lei sem sua razão de ser.

0 jurisconsulto deve ter uma critica sua, um juizo proprio; nada está acima de seu contraste, nem mesmo um aresto dez vezes confirmado. Haveria orgulho e imprudencia $\mathrm{cm}$ colocar, como pensador, sua razão acima da razão comum, e em precipitar-se, como jurisconsulto pratico, numa derrota certa; mas, do respeito á opinião de 
outrem, que tem por si as aparencias da verdade e de fato o poder coercitivo, ao servilismo do rabula, que numerará os arestos, e nāo pesa as razões, a distancia é grande: no dia em que os processos do leguleio tivessem tornado dispensaveis as meditações dos jurisconsultos concienciosos, a Ciencia do Direito estaria morta".

Não despreze a Mocidade academica essa advertencia judiciosa e util; antes, a aceite como um bom conselho e segure, com ambas as mãos, a Filosofia do Direito, que é o guia seguro do jurisconsulto.

Falei de jardim, de ciencia e de flôres e isto me recorda outra advertencia, bem digna de gravar-se aqui.

Alguem disse:

"A ciencia é um jardim, a literatura é a flôr. Sem a flôr, que beleza terá o jardim?"

Si, como diz o Abbade Bautain "Art de parler en public":

"Deus esparge seus dons, como lhe apraz, e cada arvore dá frutos segundo sua especie"

e entre os dons que Deus me deu, falta a flôr da literatura, nem porisso deixarei o jardim, de que venbo tratando, desprovido de beleza, porque pedi, de emprestimo, a LAMARTINE, apud Aprigio Guimarães, que me ajudasse neste proposito, e ele, bondosamente vem em meu auxilio, fornecendo as flôres preciosas de sua invejavel literatura.

Antes de dar a palavra a LAMARTINE, preciso ponderar, não se veja na minha preferencia por esse literato, alguma cousa de despeito, de inveja ou de sentimento por ser eu um velho.

"Viva a mocidade, contanto que não dure sempre" Disse LAMARTINE.

Todo mundo lhe sorri, mas, por que? Porque a mocidade é uma graça, uma esperança, ainda mais uma promessa. Se fica eternamente graça, nunca será força; se eternamente esperança, nunca será realidade; se eternamente promessa, nunca será frutificação.

"Se é belo florescer, é mais belo amadurecer, transformar sua mascula adolescencia em forte virilidade; é mais belo descobrir horizontes mais severos, mais tristes, porém mais verdadeiros, sem empalidecer, nem recuar no caminho; ver, sem chorar, palidas e secas, as rosas da aurora; avançar sempre corajosamente tingindo com o sangue de seus pés as rudes asperezas do caminho. Se é belo ser menino, é mais belo ser homem, filho, esposo, 
pae, pendido gravemente sobre os deveres penosos da: existencia, artista sério, cidadāo util, filosofo pensativo, soldado da Patria, martir de uma razão desenvolvida pela reflexão e pelo tempo.

Quando os antigos quiseram exprimir ein uma só figura a suprema beleza fisica do homem, esculpiram APOLLO aos 30 anos, quando a suprema força, HERCULES aos 40 anos; quando a suprema beleza moral e intelectual, o velho HOMERO"

Fiquem meditando bem nestas verdades, enquanto que este velho, com a conciencia da sua desvalia, vai deixar de aborrcer mais o bon'doso auditorio.

Finalizando, puis, que dizer do perfume das flores colhidas, proporcionalmente, em cada um dos cinco anos que se evolveram no nosso jardim de estudos cientificos, senão que ele se difunde e se evola nas asas de uma esperança, para gaudio nosso, engradecimento dos que empregaram os esforços das suas inteligencias, e para satisfação de todos que me ouvem bem dizendo desses lutadores, que, zelando o fogo de Vesta, estudam e trabalham, pelo triunfo proprio, da humanidade e da nossa Patria.

Está encerrado o curso de 1934.

Ao professor dr. Jorge Americano foi em seguida dada a palavra para saudar, em nome da Faculdade, o dr. Pacheco Prates, lente catedratico de Direito Civil, e os funcionarios compulsoriamęnte aposentados, dr. Julio Maia, secretario, e Antonio José de Freitas, amanuense. Usou tambem da palavtra o sr. João Paulo de Arruda, primeiro orador do Centro Academico XI de Agosto e o academico Pero Netto.

\section{Discurso do acadêmico João Paulo de Arruda}

Senhores :

A solenidade do encerramento das aulas dos cursos juridicos, reunindo professores e alunos, propicia ocasião para, mais uma vez, nos referirmos á creação da Lniversidade de S. Paulo.

Aspiração antiga, tantas vezes pleiteada, no corrente ano caninhou para sua definitiva realização pelo decreto que a instituiu.

A importancia dêsse fato, ultrapassa o limite das questões da Instrução Pública, para alcançar uma grande significação nacional. 
Efetivamente a Universidade é o grande laboratório onde, formando-se a geraçāo do futuro, prepara-se a própria sociedade de amanhã.

Em todas as épocas as minorias estiveram na vanguarda dos acontecimentos históricos.

Ás elites de ação e cultura, portanto, que a Universidade constituir no Brasil, caberá abrir os grandes roteiros na nacionalidade.

Por essa razão se nos afigura que na hierarquia das preocupações que incumbem ao Estado Brasileiro, o problema da formaçāo das elites deve ter prioridade sôbre o problema do ensino extensivo da generalidade da população.

A vulgarização xtensiva dos conehcimentus primarios e gerais é um ideal revestido de beleza mas a compreensão nítida dus fatos determina-nos o juizo enunciado.

E' incontestavel a impraticabilidade de alfabetizar a nossa população perdida cm imenso territorio sem comunicações, acrescendo ainda a pobreza da nossa administração pública e a desorganização do Estado.

Impōe-se preliminarmente crear a Lniversidade favorecendo assim a formação de una elite nacional que na legislatura e no govêrno, organizará, então, a nacionalidade em fundamentos cientificos e verdadeiros.

$O$ regimen de ensino superior que praticamente ainda subsiste, embora o Govêrno do Estado já tenha, com louvavel bôa vontade, expedido providencias reformadoras, nāo realiza o alto desideralum de preparar a geraçāo do futuro para a sua aluação en pról da coletividade.

Continua o isolamento das várias escolas superiores, siluadas a grandes distâncias, com o que é impossivel estabelecer-se a cunvivência dos alunos; não se crearam ainda as residências para os universitarios do interior ou de outros Estados, o que feito os preservaria do ambiente vicioso da cidade, e, ao mesmo passo, atraindo estudantes de todos os recantos da Pátria, faria de São Paulo, certamente, a Atenas Brasileira; despreocupa-se o programa de ensino da formação física e moral dos alunos, atendo-se apenas a sua instrução intelectual; não se concedeu o tempo integral aos professores, que por isso são arrastados a preocupações albeias ao magisterio. Ha ainda uma série imensa de providências que reclamam solução imediata.

Mantida a situação atual, as Escolas Superiores de S. Paulo quando muito formariam técnicos - médicos, engenheiros, advogados. O cidadão, a elite nacional, só a Universidade!

A inoperância do atual regimem de ensino, manifesta-se especialmente no Curso de Direito, que é naturalmente, pela natureza de 
seus estudos, aquele onde mais diretamente se toma contacto com a organização da sociedade.

Tal qual se faz a transmissão simples dos principios juridicos, das doutrinas do direito, - aformoseia a inteligência da juventude. Formam-se individualidades dignas de fulgurarem nos debates estéreis da Sociedade das Nações...

Mas, não se formam os construtores que a nacionalidade reclama! Não se formam os conhecedores da indole do nosso povo, dos problemas do nosso país!

E, tanto assim é verdade que, percorrendo os anais da Câmara, no Império ou na República, encontraremos passagens dignas dos parlamentos europeus. Pouco veremos, no entanto, que realmente se refira aos problemas legitimamente nacionais.

A nossa lgislação se inspirou demasiado nos grandes figurinos do liberalismo inglês de 1789, perdendo de vista as idiosincrasias e particularidades caracteristicas do meio brasileiro.

Exemplo frizante do desconhecimento das nossas realidades por parte dos homens oriundos das nossas Academias, é a adoção do sufragio universal direto no Brasil.

Percorri cuidadosamente os arquivos onde se acumulam os requerimentos para qualificação de eleitores: deparei grande porcentagem de requerimentos onde a grafia do peticionário é um verdadeiro desenho, copiado com sacrificio facilmente imaginável.

Neles, as palavras não foram escritas, mas foram, sim, desenhadas!

Como poderão tais eleitores, que rabiscam tão dificilmente os nomes, escolher os legisladores e governantes?

$\mathrm{Na}$ Inglaterra, cujas leis constitucionais foram conquistadas em lutas sangrentas pelos barões; pais que tem uma secular tradiçẵo politica, onde a situação económica já marcou profundamente a existência das classes, e os partidos politicos existentes encarnam, na verdade, cada um o interesse de determinada classe, pode justificar-se a prática do sufrágio universal direto.

No Brasil, de forma alguma.

Figuremos a hipótese de uma eleição numa das muitas cidades do maravilhoso interior paulista.

Suponhamos que disputam as eleições para a Câmara Federal dois cidadãos, sendo o primeiro partidário do "Livre Câmbio" e o segundo a favor do "Protecionismo alfandegário"

Pergunto: -- o eleitor, sitiante, funcionário, vendeiro, caixeiro, qualquer que fôsse en regra, poderia escolber entre um e outro candidato conscientemente?

Saberia êle distinguir qual a politica mais útil aos interesses suncriores da colectividade? 
Saberia êle o que significam "Livre câmbio" e "protecionismo"?

Evidentemente nãol Tanto que os nossos candidatos não têm programa.

As nossas campanhas eleitorais discutem, não a organização do Estado - si deve ser parlamentar ou presidencialista - mas, decaem dos altos planos da politica para os baixos niveis de uma politiquice liliputiana.

A impraticabilidade do sufrágio universal direto evidencia-se ainda pelo manifesto desinteresse do povo relativamente aos prélios eleitorais.

Somai os eleitores de todo país, para cujo alistamento a lei e o interesse dos candidatos tanto concorreu, e verificareis a minima porcentagem que representam no total da populaçāo.

Tambem a inadatação do voto universal direto no Brasil resulta do facínio, que o poder exerce sôbre a nossa população, o que levou o sr. Oswaldo Aranha a afirmar que, no Brasil, o prestígio politico deriva do cargo.

Essa incompreensão da realidade brasileira, flagrante em nossa legislação, como exemplifica a adoção do voto universal direto, é uma consequência da defeituosa organização, a que nos referimos, do ensino superior em nosso país.

Nas nossas Escolas de Direito faz-se apenas transmissāo dos principios e doutrinas exóticas, mas não ha a investigação da realidade social, nem a concepção de normas originais a ela adatáveis.

Essa profunda divergência que se verifica entre os homens de cultura acentuadamente européa e a sociedade nova dos paises sul americanos, tem um retrato fidelíssimo nas páginas de "Facundo" a grande e imortal obra prima da literatura argentina.

Sarmiento, cujo espirito se formara na leitura dos livros e teorias dos pensadores do velbo mundo, nāo sabia compreender a realidade rústica e indiciplinada que o caudilho Juan Facundo Queiroga, em parte encarnava.

Hoje tambem as naçōes sul-americanas reclamam homens que as compreendam. Esses serão, então, os continuadores de Bolivar e do Partiarca.

Depois dos paladinos da independência são precisos os constructores da ordem social.

A tarefa de formar tais constructores da ordem social, é da Universidade. Cooperemos para a sua realização já iniciada pelo atual Govêrno do Estado.

Sãd Paulo, abrigando uma Universidade permanecerá fiel ás suas tradições. 
Na Baía, ouvi de um fervoroso amigo de São Paulo, a narrativa do conselho que o grande presidente Gois Calmon dera ao seu filho, ao concluir êste o curso secundário:

- Meu filho, vá estudar na Faculdade de Direito de São Paulo. Lá se aprende a ser brasileiro.

De fato, o designio curioso da coincidência denominou São Paulo ao territorio bandeirante, como se quisesse com isso, marcar as directrizes do seu povo pelo modêlo maravilhoso do seu padroeiro - o apóstolo São Paulo.

A creação da Universidade se enquadra nas directrizes salutares da nossa tradição social.

Voltemos os olbos para o passado, e as páginas cheias de inefável encanto da nossa história, serão um incentivo para essa mar. cha em busca do ideal!

Em resposta, falaram os srs. dr. Pacheco Prates e dr. Julio Maia, que agradeceram a homenagem que lhes estava sendo prestada, e que, ao terminar, foram muito cumprimentados pelos seus colegas e amigos presentes.

\section{Discurso do Dr. Julio Maia}

Exmos. Srs. Drs. Reitor da Universidade de São Paulo e Diretor da Faculdade, Exmos. Srs. Drs. Interventor interino, Secretarios do Estado, Chefe de Policia, Professores, minhas senhoras e meus senhores.

Esta homenagem da Congregação da Faculdade de Direito de ذão Paulo é prestada ao professor Dr. Manoel Pacheco Prates, ao amanuense Antonio José de Freitas e a mim, como secretario, a nós três, que fomos aposentados compulsoriamente pelo Presidente da Republica, por Decreto de $1 .^{\text {a }}$ de outubro findo, na conformidade do n. 3 do art. 170 da Constituição, por termos atingido 68 anos de idade.

Quanto a mim, devo aqui recordar que essa resolução do Governo da Republica me alcançou, quando eu já tinha prestado cerca de 50 anos de scrviços publicos a esta tradicional Faculdade, pois, desde moço, apenas bacharel formado por este mesmo Instituto, a 5 de novembro de 1884 , cinco meses depois de receber o respectivo grau, para aqui voltei trazido pela benevolencia do então diretor, o Cons. Dr. André Augusto de Padua Fleury, a ser um dos seus auxiliares.

Nomeado oficial da secretaria por Portaria do Governo Imperial, de 21 de Abril de 1885, esse ato emanado do partido liberal, entāo, no poder, foi surpresa para mim, pois, eu era militante no 
partido conservador, na facçāo chefiada pelo emerito jurisconsulto e notavel advogado Dr. João Mendes de Almeida, a cujo conselho aceitei o lugar, no qual tomei posse, a $10^{\circ}$ de junho seguinte, entrando, desde, entāo, em exercicio.

No dominio da Republica, com a reforma do Ensino Juridico, constante do Decreto n. $1.232-\mathrm{F}$, de $10^{\circ}$ de janeiro de 1891 , fui nomeado por Decreto do Governo, de 21 de Maio desse mesmo ano, para o cargo de sub-secretario desta Faculdade, tendo tomado posse e entrado no exercicio do cargo, a 6 de abril seguinte, exercendo tambem então, ex-vi do disposto no art. 455 do citado Decreto $n .^{\circ}$ 1.232-F, o cargo de secretario do então Curso Anexo á Faculdade, o qual foi reorganizado sob novas bases pela referida Reforma.

Devo essa nomeação á benignidade do Conselheiro Dr. Carlos Leoncio de Carvalho, que foi lente e diretor desta Faculdade.

Em 1903, quando Presidente da Republica o Conselhciro Dr. Francisco de Paula Rodrigues Alves, eminente paulista, fui nomeado por Decreto de 6 de julho, para o cargo de secretario, na vaga verificada pela aposentadoria do Dr. André Dias de Aguiar, tendo tomado posse e entrado no exercicio desse cargo, a 9 clesse mesmo mês.

Nesse longo periodo de tempo, de abril de 1885 a setembro de 1934, dois terços da minha vida, procurei auxiliar, tanto quanto possivel, a todos os diretores, quer efetivos, quer interinos, que administraram este tradicional Instituto de Ensino Superior, amenizandolhes a tarefa, para o que, aqui trabalhava ao correr do dia, desde muito cedo e, ás vezes, até ao anoitecer, como podem atestar diversos lentes, e, durante a noite, em minha residencia, para onde mandava o serviço urgente do expediente do dia, como podem tambem confirmar todos os funcionarios, executando todos os serviços atribuidos ao meu cargo, sob a administracão de nada menos de 15 diretores sucessivos, tendo apenás em atenção à lei e á justiça e, algumas vezes, á equidade, sempre porém, assumindo a responsabilidade dos meus atos e dos que, por determinaça minha, eram praticados pelos diversos funcionarios da secretaria.

No desempenho dos cargos, que aqui exerci, sendo eu de genio um tanto retraido, talvez, tivesse desagradado alguem, sendo provavel que tivesse adquirido algum desafeiçoado, pois, por aqui passaram muitos milhares de pretendentes a matricula nos cursos desta Faculdade, alguns ainda na aurora da jurentude, muitos já de maior idade e outros já homens icitos, ans quais nāo pude satisfazer nas suas esdruxulas pretensões.

$\mathrm{Se}$, ás vezes, fui julgado exigente $\mathrm{cm}$ pareceres, então, dados por mim, nāo me lancem culpa, mas, se insurjam contra a lei, a cuja obediencia cu eslavia obrigado. 
Diz-me a conciencia que, na repulsa de desejos desarrazoados. nenhum prejuizo causei a quem quer que fosse, nada, portanto, graças a Deus, tendo de que me penitenciar, até esta data, em maleria atinente ao serviço publico.

Alguns dos 15 diretores, que dirigiram os destinos desta casa, a partir do Dr. Herculano de Freitas até o Dr. Waldemar Ferreira, que preside á presente sessão, inclusivé o Dr. Reynaldo Porchat, reitor da Universidade de São Paulo, e todos os atuais professores desta Faculdade, e mesmo alguns já jubilados ou aposentados aqui fizeram o seu curso academico, ao tempo, em que fui funcionario.

Das sucessivas gerações de academicos que durante a minha aprendizagem de funcionario, perlustraram os humbrais e as salas deste mais que secular edificio, templo de ciencia e de civismo, muitos deles notaveis e cujos nomes não preciso mencionar, para me não tornar fastidioso, e são, por demais, conhecidos por todos nós brasileiros, abrilhantaram e ainda abrilhantam, no país e fóra dele os diferentes ramos da atividade humana, desempenhan'do altas funções na governança e na magistratura da União e dos Estados, na diplomacia, na direção de modelares institutos de Ensino superior, na politica, no parlamento, na advocacia, na medicina e na cirurgia, na engenharia, nas finanças, no jornalismo, no comercio, nas industrias e na lavoura, e de todos eles ainda conservo gratas e impereciveis recordações pela distinção, com que sempre me trataram e pela amizade, com que ainda me cativam.

Aluno, que fui do extinto curso anexo a esta Faculdade, onde me matriculei e prestei os exames do curso secundario, iniciado no antigo seminario episcopal, então, dirigido por frades capuchinhos, todos versadissimos nas materias, que ensinavam, habituado, por isso, a rigorosa disciplina, ao estudo e a obediencia á lei e aos superiores hierarquicos, e, depois, aluno dos cinco anos do curso superior desta memoravel Faculdade, ouvindo, desde então e, sem cessar, falar das suas gloriosas tradições, ao cntrar pouco depois de bacharel formado em direito, a fazer parte do corpo administrativo deste instituto, pocurei, na medida de minhas forças, conservar as noticias dos fatos historicos, transmitidias de gerações a gerações, desde a instalação do curso juridico, aqui, em São Paulo, noticias essas, que estavam guardadas com chave de ouro, no arcaboico do antigo convento de São Francisco, assim, então, conhccido, para que não houvesse solução de continuidade, nessa preciosa reliquia dos nossos antepassados.

Eis, ai, meus senhores e minhas senhoras, a descrição singela e sem estilo da vida de quasi 50 anos de um funcionario publico. e não de um secretario de 400 anos, camo disse, no seu bom humor, um jovem quinto anista formado, no começo deste ano, quasi toda ela 
passada debaixo dessas grossas paredes, feitas de taipas de pilāo, deste magestoso edificio, que é a tradicional Faculdade de Direito de São Paulo, o qual, se outra cousa mais proveitosa aqui nāo fez, ao menos, empregou o seu tempo, mandando corrigir os erros ortograficos e de sintaxe, colocar as estampilhas, que faltavam, repelindo, com leve admoestação, as não adequadas, e providenciando com animo e prudencia sobre assunto de somenos importancia, pelo que era tido e havido como exigente e ranzinza, mas, não obstante, se esforçou em manter a lei, a ordem e a disciplina e soube captar a simpatia dos lentes, da classe academica e dos scus auxiliares, os quais, por varias vezes, lhe deram justos motivos de jubilo e de grande apreço, amenizando-lhe assim a sua ardua tarefa.

Agora, meus eternos agradecimentos á ilustrada Congregação dos Professores, que promoveu esta homenagem, ás brilhantes e bondosas palavras, com que me saudou o joven e apreciado orador, representante do Centro Academico XI de Agosto, á classe academica a demonstração de afeto, que sempre me dispensou, e aos funcionarios, que aqui ficam, a dedicação, com que se portaram, na execução dos serviços, durante o tempo, em que dirigi a Secretaria; a todos, enfim, Professores, academicos e funcionarios. meus mais sinceros agradecimentos pela coadjunção no desempenho desse meu espinhoso cargo. De todos levo imorredouras saudades e a todos apresento as minhas despedidas.

Ao encerrar-se a sessão, o professor $\mathrm{dr}$. Reynaldo Porchal declarou inaugurada a nova sala de aulas sob o nome de "Sala Joāo Mendes Junior"

A essa expressiva homenagem á memoria do grande jurisconsulto, professor e magistrado brasileiro, estiveram presentes membros da familia do dr. João Mendes Junior, dentre os quais o seu irmão dr. Angelo Mendes de Almeida.

\section{DR. JULIO MAIA}

\section{ARTHUR F. DE OLIVEIRA}

Artigo publicado na "Terra Vermelha" "orgâu dos academicos de direito da colonia de Ribeirão Prelo", fasc. 5, Novembro de 1934.

Ainda sôam claramente em meus uuvidos os calorosos aplausos com que a mocidade academica da Faculdade de Direito de São 